\title{
Emotional Intelligence, Resilience, Self-care, and Self-leadership in Healthcare Workers Burnout: A Qualitative Study in Coaching
}

\author{
Zeina Ghossoub, Relly Nadler, Naim El-Aswad* \\ Vital Signs Vital Skills, L.L.C., 2363 Turnbury Elm Ct, Spring, TX 77386, United States
}

Received May 30, 2020; Revised July 3, 2020; Accepted July 29, 2020

Copyright $\bigcirc 2020$ by authors, all rights reserved. Authors agree that this article remains permanently open access under the terms of the Creative Commons Attribution License 4.0 International License

\begin{abstract}
Burnout is an epidemic among physicians, nurses, and healthcare workers. Unique to burnout is its severe morbidity and mortality consequences on professionals and patients alike. Solutions to combat burnout are either focused on antecedent factors, or on the individual professional. Of the individual approaches, coaching, emotional intelligence, self-leadership and self-care skills and tools have shown promise in creating a positive impact. Several obstacles linked to cost, time restraints, and delivery methods have led to limiting the potential effects of these approaches. In 2018, a group of 70 nurses and allied healthcare professionals underwent a 6-hour workshop focusing on burnout and the above-mentioned approaches. Subjective evaluation of the immediate impact was analyzed. 7 months later, another subjective survey was conducted to test the impact of the workshop on its desired goals. The results show a measurable positively powerful change that was maintained throughout. Discussion of the importance of coaching, its delivery method, and the reasons for its success follows. The results show that using group coaching while honoring the adult learners' characteristics and relying on intrinsic motivation are very powerful tools that the healthcare industry and coaches alike can use to help in fighting the epidemic of burnout.
\end{abstract}

Keywords Burnout, Emotional Intelligence, Self-leadership, Self-care, Nursing Burnout, Coaching

\section{Introduction}

Burnout is a condition characterized by lack of empathy, cynicism, a sense of lack of meaning in work, emotional exhaustion, feeling ineffective, and a propensity to look at people and patients as objects rather than human beings (Shanafelt et al, 2015). There is a high prevalence of burnout among nurses (Guo et al, 2018). Literature shows that 33 to $43 \%$ of nurses experience at least one component of burnout (Reith, 2018). In 2017, a research conducted by RN network showed that among the 600 nurses surveyed nationwide, around half of them considered leaving the profession (Anonymous, 2017). Compared to two years prior, nurses feel their work overload has increased by $46 \%$. There are several studies reflecting the same issues that were found in the survey, being overworked, being bullied by other nurses, physicians and administrators, being occupied with paperwork and electronic medical records, a decrease in work-life balance, and being faced with worsening national nursing shortages. In 2017, Bakhamis, Smith, Coustasse, and Paul summarized the four main factors that are behind nursing burnout: individual, management, work characteristics and organizational. According to Christina Maslach, burnout can be traced to three main causative factors: Insufficient rewards, unmet expectations, and lack of control (Maslach \& Zimbardo, 2003). Stress and burnout lead to several personal and professional consequences, including but not limited to, medical errors, lapses in judgement, depression and lateral violence, decrease in attention and memory, high nursing turnover, nursing shortage and an association with at least one chronic health condition (Botha, Gwin, \& Purpora, 2015). Because of the effects of burnout on nurses, patient care, and hospitals, there has been a plethora of research looking at ways to control it, minimize it, manage it, and treat it.

The two general ways burnout is approached has been either to target the antecedent factors or factors outside the control of the nurse such as work environment (Nantsupawat et al, 2017), inadequate staffing (Dutra, Cimiotti, Guirardello, 2018), and perceived organizational 
politics (Labrague et al, 2016) or to focus on helping individuals/nurses deal with burnout and their work. Of the latter approach, resilience, coping abilities, emotional intelligence, and self-care have been the subject of recent investigation. What the literature has shown so far is that resilience training, coping abilities, and mindfulness (Braun, Kinser, Carrico \& Dow, 2019; Guo et al, 2018; Van Wietmarschen, Tjaden, van Vliet, Batties-Fires \& Jong, 2018), emotional intelligence (Codier, Kooker \& Shoultz 2008; Gorgens-Ekermans \& Brand T, 2012; Morrison, 2008; Sczcygiel \& Mikolajczak, 2018), and self-care (Hlubocky, Back \& Shanafelt, 2016; Runyan, Savageau, Potts \& Weinreb, 2016; Salmoirage-Blothcer et al, 2016; Schrijver, Brady \& Trocket, 2016) lead to not only decreasing the prevalence of burnout but also mitigating and sometimes reversing its effects. Another key factor in combating burnout and maximizing productivity and clinical skills is self-leadership (El-Aswad, Ghossoub \& Nadler, 2017; Elloy \& Patil, 2014; Ghossoub, Radler \& El-Aswad, 2018).

In order to study the effects of these factors on burnout, a qualitative study was conducted in one of the community hospitals in Houston. The approach used focused on coaching techniques, individuals and groups. There is enough medical and scientific evidence that not only shows coaching to have a positive impact on health care, but that there is a movement towards relying on it to achieve the best possible results. Health coaching can improve and have a positive impact on chronic disease interventions (Adams et al, 2013). Life coaching (coaching and helping others achieve personal and professional life goals) improves self-efficacy and self-empowerment (Ammentorp et al, 2013). Health coaching (coaching others to achieve desired health goals) is essential for changes in health-related behavior (Neuner-Jehle, Schmid $\&$ Gruninger, 2013). Coaching healthcare workers such as physicians have been shown to help combat burnout. (Schneider, 2014) Coaching can also be applied on a group level as it has shown to be a cost-effective approach to enhance change among several individuals simultaneously (Armstrong et al, 2013).

\section{Purpose}

This study was intended to look at the effect of a brief (6-hour) group coaching workshop using emotional intelligence, resilience, self-care, and self-leadership techniques in combating nursing and healthcare workers' burnout. The qualitative study looked at the impact the workshop had on inducing behavioral change that will help participants deal with burnout and the sustainability of these changes over a period of 7 months.

\section{Methodology}

In June of 2018, 70 employees from a community hospital in the Houston area attended a six-hour workshop. The employees, who were assigned and chosen by the hospital, were a mix of leaders from the professions of nursing, radiology, respiratory therapy, and radiology. Data was not gathered on how many were from each department. They were all either floor charge nurses or unit or shift supervisors. Although age and gender were asked, few provided the answers which did not allow the researchers to use or discuss this data. The workshop was divided into two parts.

The first part, the Awareness part, was a one-hour introductory presentation on the definitions of burnout, stress, emotional intelligence, resilience, wellness, self-care, and self-leadership. Discussion of the pathophysiology of burnout and stress, followed by the effects of individual self-care, resilience, and self-leadership in the healthcare industry introduced the participants to the topic and the rationale behind the workshop. The researchers had introduced this approach, the AAA approach (Awareness, Acknowledgement, Action) in prior workshops and research and found significant success with its intended objectives (Ghossoub et al, 2018).

The second part was the "Action" part of the AAA approach. During this time, the participants were introduced to action steps, tools, coaching processes, exercises, and approaches in self-care, resilience, and self-leadership. Specific areas targeted included practicing mindfulness, stress reduction techniques, stress optimization techniques, resilience training exercises, enhancing emotional intelligence tools, and self-leadership development. Coaching was used as the main approach of education and training. Coaching enhances self-awareness and promotes self-growth. Coaching uses innate strengths and abilities and helps people maximize them to reach their true potential (Gazelle, Liebschutz, \& Riess, 2015). Group coaching is also an effective modality as it has shown to be a cost-effective approach to enhance change among several individuals simultaneously (Armstrong et al, 2013). Using coaching techniques that focus on improving self-awareness, self-care, self-compassion, and boundary setting have led to behavioral changes among physicians and improved patient care (Schneider, 2014).

The acknowledgement part of the AAA approach was not conducted due to primarily cost of covering assessment tools such as the Maslach Burnout Inventory or Emotional Intelligence Quotients. The participants were informed of such tools. They were asked about their subjective feelings and perceptions of being burned out.

At the end of the workshop, evaluation surveys were submitted. 63 surveys were collected to evaluate the program and its impact on burnout, mindfulness, resilience, stress, and mindfulness. 7 months later, follow up surveys were sent via email. 43 surveys were collected via email which yielded a $68 \%$ yield for comparison. The survey evaluated the awareness and the action parts of the 
workshop. The researchers wanted to understand the impact of the workshop in four ways:

a. How much of the information had been retained?

b. What effect, if any, did the awareness part of the workshop have on the participants?

c. What action steps or tools, if any, were the participants using?

d. What were the perceived effects the workshop had on burnout, self-care, resilience, patient care, and stress?

\section{Results}

Overall, the results of the intervention were encouraging. At the end of the workshop, the participants were given a survey that documented their knowledge and awareness about the pathophysiology and symptoms of burnout, about the changes in the brain that occur because of burnout, about the impact of mindfulness on burnout and performance, about the tools and effects of resilience training and positive stress mindset. (Table 1). On a scale of 1 (not aware) to 5 (Very aware), the participants scored an average of 2.51 prior to the workshop and that average jumped to 4.84 after the workshop (Table 1). This confirmed that one of the goals of the workshop was successful in increasing the awareness of the participants. In this case, it was an average of $94 \%$. Over $96 \%$ noted the perceived improvement in competence, performance, and patient outcomes (Table 2).

Table 1. Survey questions on awareness 7 months after the workshop

Scale used was a range from 1 (Not Aware) to 5 (Very Aware):

\begin{tabular}{|c|c|c|}
\hline Survey Question & $\begin{array}{c}\text { Before Workshop } \\
\text { (Average) }\end{array}$ & $\begin{array}{c}\text { After Workshop } \\
\text { (Average) }\end{array}$ \\
\hline How well were you aware of the symptoms of burnout? & 3 & 4.92 \\
\hline How well were you aware of pathophysiology of burnout? & 2.2 & 4.81 \\
\hline How well were you aware of the changes in your brain because of burnout? & 2.2 & 4.87 \\
\hline $\begin{array}{c}\text { How well were you aware of the effects and tools of mindfulness on you and your } \\
\text { performance? }\end{array}$ & 2.54 & 4.78 \\
\hline $\begin{array}{c}\text { How well were you aware of the effects and tools of resilience training on you and } \\
\text { your performance? }\end{array}$ & 2.24 & 4.85 \\
\hline $\begin{array}{c}\text { How well were you aware of the effects and tools of positive stress mindset on you } \\
\text { and your performance? }\end{array}$ & 2.85 & 4.84 \\
\hline Overall Average & 2.51 & \\
\hline
\end{tabular}

The survey showed an average of $94 \%$ improvement in the scores.

Table 2. Perceived effect of the workshop on competence, performance and patient outcomes

\begin{tabular}{|c|c|c|c|}
\hline $\begin{array}{c}\text { Please rate the projected impact of this CME activity on your } \\
\text { performance, and/or patient outcomes: }\end{array}$ & & & \\
\hline $\begin{array}{l}\text { This activity increased my competence*. } \\
\text { (number of participants) }\end{array}$ & $\begin{array}{c}\text { NO } \\
\text { INCREASE } \\
(2)\end{array}$ & $\begin{array}{c}\text { MODERATE } \\
\text { INCREASE } \\
(9)\end{array}$ & $\begin{array}{c}\text { GREAT } \\
\text { INCREASE } \\
(51)\end{array}$ \\
\hline $\begin{array}{l}\text { This activity will improve my performance**. } \\
\text { (number of participants) }\end{array}$ & NO IMPACT & $\begin{array}{c}\text { MODERATE } \\
\text { IMPACT } \\
\text { (8) }\end{array}$ & $\begin{array}{l}\text { HIGH IMPACT } \\
\quad(52)\end{array}$ \\
\hline $\begin{array}{l}\text { This activity will improve my patient outcomes } \\
\text { (number of participants) }\end{array}$ & $\begin{array}{l}\text { NO IMPACT } \\
\text { (1) }\end{array}$ & $\begin{array}{c}\text { MODERATE } \\
\text { IMPACT } \\
(10)\end{array}$ & $\begin{array}{l}\text { HIGH IMPACT } \\
\quad(50)\end{array}$ \\
\hline
\end{tabular}

Summary: Over $96 \%$ noted the perceived improvement in competence, performance, and patient outcomes.

A: 7 months follow up results: 
After 7 months, the participants were surveyed again with respect to the awareness and knowledge and symptoms of burnout, stress mindset, mindfulness, and the brain changes during burnout. (Table 3) Of the 41 who answered, less than $2 \%$ felt their knowledge since the workshop had decreased, about $26 \%$ noted their knowledge was about the same, and around $72 \%$ noted that their knowledge had increased even more. The reasons behind these results were not explored. When asked about the tools they were given and how often they were using them or relying on them, over $90 \%$ of participants continued to use the tools at least a few times after 7 months, with $54 \%$ using them frequently or often. (Table 4) Further, $75 \%$ of the participants either agreed or strongly agreed that they have improved along several target points related to self-leadership, burnout, emotional intelligence, resilience, and self-care. (Table 5).

Table 3. Impact on awareness after 7 months

Scale: 1(Decreased), 2(same), 3(Increased)

\begin{tabular}{|c|c|c|c|}
\hline Question/Number of participants & 1(Decreased) & 2(Same) & 3 (Increased) \\
\hline My awareness of the symptoms of burnout is & 1 & 9 & 30 \\
\hline $\begin{array}{l}\text { My awareness of the pathophysiology of burnout } \\
\text { has improved }\end{array}$ & 1 & 11 & 28 \\
\hline $\begin{array}{l}\text { My awareness of the changes in my brain because } \\
\text { of burnout has improved }\end{array}$ & 1 & 11 & 28 \\
\hline $\begin{array}{l}\text { My awareness of the effects and tools of } \\
\text { mindfulness on me and my performance is the same }\end{array}$ & & 14 & 26 \\
\hline $\begin{array}{l}\text { My awareness on the effects and tools of resilience } \\
\text { training on me and my performance is the same }\end{array}$ & 1 & 10 & 29 \\
\hline $\begin{array}{c}\text { My awareness on the effects and tools of positive } \\
\text { stress mindset on me and my performance is the } \\
\text { same }\end{array}$ & & 9 & 32 \\
\hline Average & $\begin{array}{l}\text { Less than } 2 \% \text { felt their } \\
\text { knowledge decreased }\end{array}$ & $\begin{array}{c}\text { Around } 26 \% \text { felt their } \\
\text { knowledge was the same }\end{array}$ & $\begin{array}{l}\text { Around } 72 \% \text { felt their } \\
\text { knowledge had increased }\end{array}$ \\
\hline
\end{tabular}

Table 4. Summary of tools practiced after 7 months

Scale: 1 (No) 2 (Once) 3 (A few times) 4 (Often) 5 (Frequent)

\begin{tabular}{|c|c|c|c|c|c|}
\hline $\begin{array}{c}\text { Question/Number of } \\
\text { participants }\end{array}$ & 1 (No) & 2 (Once) & 3 (A few times) & 4 (Often) & 5 (Frequent) \\
\hline $\begin{array}{c}\text { I practice } \\
\text { mindfulness }\end{array}$ & 2 & 2 & 11 & 16 & 10 \\
\hline $\begin{array}{c}\text { I use the emotional } \\
\text { audit }\end{array}$ & 5 & 6 & 13 & 12 & 5 \\
\hline $\begin{array}{c}\text { I use the empathy } \\
\text { audit }\end{array}$ & 3 & 5 & 12 & 11 & 9 \\
\hline $\begin{array}{l}\text { I use the techniques } \\
\text { taught at the } \\
\text { workshop for } \\
\text { resilience }\end{array}$ & 2 & 6 & 12 & 15 & 6 \\
\hline $\begin{array}{l}\text { I rely on the positive } \\
\text { stress strategies } \\
\text { taught in the } \\
\text { workshop }\end{array}$ & 2 & 3 & 12 & 17 & 7 \\
\hline $\begin{array}{l}\text { I practice self-care } \\
\text { and wellness } \\
\text { strategies taught in } \\
\text { the workshop }\end{array}$ & 3 & 2 & 14 & 15 & 7 \\
\hline Average & $7 \%$ & $9 \%$ & $30 \%$ & $35 \%$ & $19 \%$ \\
\hline
\end{tabular}

Over $90 \%$ of participants continued to use the tools at least a few times after 7 months, with $54 \%$ using them frequently or often. 
Table 5. Subjective evaluation of performance because of the workshop

Scale: 1 (Strongly Disagree) 2 (Slightly Disagree) 3 (Neither Agree nor Disagree) 4 (Slightly Agree) 5 (Strongly Agree)

\begin{tabular}{|c|c|c|c|c|c|}
\hline+2 & $\begin{array}{c}1 \text { (Strongly } \\
\text { disagree) }\end{array}$ & $\begin{array}{l}2 \text { (Slightly } \\
\text { disagree) }\end{array}$ & $\begin{array}{c}3 \text { (Neither agree } \\
\text { nor disagree) }\end{array}$ & 4 (Slightly agree) & $\begin{array}{c}5 \text { (Strongly } \\
\text { agree) }\end{array}$ \\
\hline $\begin{array}{l}\text { I feel I am more confident in my } \\
\text { leadership role }\end{array}$ & & 1 & 6 & 15 & 19 \\
\hline I feel I am a better listener & & 1 & 5 & 16 & 20 \\
\hline I feel I am more empathetic & & 1 & 8 & 11 & 16 \\
\hline $\begin{array}{c}\text { I feel I am more emotionally } \\
\text { intelligent }\end{array}$ & & 1 & 4 & 18 & 17 \\
\hline I feel I am more resilient & & 1 & 11 & 17 & 13 \\
\hline I feel I am a better communicator & & 1 & 6 & 21 & 14 \\
\hline I feel I am less burned out & 1 & 4 & 11 & 19 & 5 \\
\hline I feel I take better care of myself & 2 & 2 & 9 & 18 & 10 \\
\hline I feel I less stressed & 1 & 6 & 10 & 18 & 6 \\
\hline $\begin{array}{l}\text { I feel I can deal with pressure in a } \\
\text { more positive way }\end{array}$ & & 2 & 5 & 20 & 14 \\
\hline Average & $1 \%$ & $5 \%$ & $19 \%$ & $42 \%$ & $33 \%$ \\
\hline
\end{tabular}

Summary: $75 \%$ of the participants either agreed or strongly agreed that they have improved along several target points related to self-leadership, burnout, emotional intelligence, resilience, and self-care.

Table 6. Summary of recommendations about the workshop

Scale: 1 (Strongly Disagree) 2 (Slightly Disagree) 3 (Neither Agree nor Disagree) 4 (Slightly Agree) 5 (Strongly Agree)

\begin{tabular}{|c|c|c|c|c|c|}
\hline Question & 1 & 2 & 3 & 4 & 5 \\
\hline I would recommend this workshop to healthcare providers & & & 2 & 6 & 33 \\
\hline $\begin{array}{l}\text { I would recommend more interventions/training/workshops targeting resilience, } \\
\text { stress mindset, and burnout }\end{array}$ & & & 1 & 5 & 35 \\
\hline $\begin{array}{l}\text { I would invest time, effort, and money in similar interventions/training/workshops } \\
\text { to this workshop because of the benefits }\end{array}$ & & 3 & 2 & 11 & 24 \\
\hline $\begin{array}{l}\text { I would recommend similar interventions/training/workshops interventions } \\
\text { (Semi-annual or annual) on burnout }\end{array}$ & & & 1 & 5 & 34 \\
\hline $\begin{array}{l}\text { I would recommend similar interventions/training/workshops interventions } \\
\text { (Semi-annual or annual) on resilience }\end{array}$ & & & 3 & 9 & 29 \\
\hline $\begin{array}{l}\text { I would recommend similar interventions/training/workshops interventions } \\
\text { (Semi-annual or annual) on stress mindset }\end{array}$ & & & 1 & 8 & 32 \\
\hline
\end{tabular}

Summary: $76 \%$ strongly recommended the contents of this workshop, this workshop, and similar workshops. The majority would invest time and effort and money in doing similar workshops again. $18 \%$ slightly agreed to recommend. About $4 \%$ were neutral.

When evaluating this workshop and its importance or impact in the participants' lives, $76 \%$ strongly recommended the contents of this workshop to other healthcare providers. $87.5 \%$ agreed that they would invest time and money in similar workshops in the future. The majority would invest time and effort and money in doing similar workshops again. $18 \%$ slightly agreed to recommend. About $4 \%$ were neutral. (Table 6 )

Finally, when asked about comments regarding the impact of the workshop on the participants, the most frequently stated comments were almost identical whether it was directly after the workshop or 7 months later. (Table 7) The participants had mentioned with the highest frequency of comments that they learned how to deal with stress better, that their knowledge and awareness of burnout had increased, that they learned the impact of being mindful, that they had become more aware of themselves and others, the realization of the importance of self-care and practicing it, practicing strategies for stress relief and resilience, and that they endorse recommending the impact and lessons learned to all staff members. 
Table 7. Summary of comments about awareness and actions

What was interesting was the comments at the end of the workshop and those after 7 months. These comments were almost identical. The participants most frequent listed comments were:

\begin{tabular}{|l|l|c|}
\hline Most Frequent Comments & Immediately After & 7 months later \\
\hline How to deal with stress better & High frequency & High frequency \\
\hline Knowledge and awareness of burnout & High frequency & High frequency \\
\hline Being mindful & High frequency & High frequency \\
\hline Using emotional intelligence & High frequency & High frequency \\
\hline Being aware of themselves and others & High frequency & High frequency \\
\hline Self-care & High frequency & High frequency \\
\hline Practicing strategies for stress relief and resilience & High frequency & High frequency \\
\hline Recommendations for all staff members & High frequency & High frequency \\
\hline
\end{tabular}

\section{Limitations}

There are several limitations to this study. The time of intervention was a 6-hour period. The results that were immediately noted could be due to the workshop. However, the observers cannot claim that the findings after 7 months were due only to the intervention. There is an assumption here that the change that occurred was primarily due to the intervention and workshop. Further, the data did not look at individuals according to gender and age and experience and specialty. How these factors could have affected the outcomes is not known. The heterogeneity of the group makes it very difficult to come up with a unified conclusion. However, the interesting observation is that despite the heterogeneity, the results were remarkably similar across all the participants. Lastly, due to the size and the nature of this qualitative approach, generalizations about recommendations would be limited. However, these observations are strong enough in the opinion of the researchers that they warrant further more structured investigations with a potential qualitative and quantitative nature to the research.

\section{Discussion}

Looking at the literature, the findings of this study reflect some of what is found in the literature: coaching, emotional intelligence, self-care, resilience training, and stress management have shown success in combating burnout. What this research set out to explore is the potential impact of group coaching on burnout using the above techniques while facing real-time constraints. A 6-hour workshop seems hardly enough to create long-lasting emotional, physical, mental, and behavioral changes to combat burnout. Yet in the practical world of healthcare, sometimes that is all that is usually afforded for training. The study shows the noticeable positive effects the workshop seems to have on its targeted goals. These results echo findings reported when similar workshops were done on around 30 physicians (Ghossoub et al, 2018).
The majority of participants achieved favorable outcomes from the workshop. Further, when those results were reassessed after 7 months, most of those who responded had retained them. The workshop introduced the topics mentioned by discussing the pathophysiology of burnout, the science behind it, the approaches to its management. It relied on the audience's experience and showed examples from their daily personal and professional lives. Once the audience understood the topic, and it resonated with them on a personal and professional basis, the presenters had the "buy in" necessary to continue. Building trust from an adult audience requires relying on the adult learners' characteristics, as will be discussed later. To provide the audience with the necessary tools and training, the presenters used coaching techniques, stressed audience participation, allowed for practicing the tools given, and helped them develop solutions based on their personal and professional work environment.

In doing so, the apparent success of the workshop can be attributed to three main factors: Intrinsic motivation, coaching, and consideration for the adult learner. Intrinsic motivation refers to behaviors that are driven by internal rewards. The "rewards" focused on in this workshop were connecting with the purpose of the participant's profession (helping others). Literature has shown that one of the most effective ways to induce long-lasting change in people is to rely on such a motivational approach (Hardcastle et al, 2015). According to Knowles, 2015, the best way to impact adults is if we honor their independence and experience, if we engage them and consider their points of views, if the approach is goal-oriented, and if the workshop is relevant to them. The workshop focused on honoring these factors through its delivery, design, content, and coaching. Special emphasis was placed on delivering the workshop through a group coaching technique/style. Coaching helps clients achieve their goals and overcome their obstacles. Coaches are the clients' partners in their journey. Coaching, along with the presentation type, helped achieve key factors that adults use to learn and implement (Loschl, Traut-Mattausch, Mühlberger \& Jonas E, 2016). Through coaching, participants were able to self-reflect on 
experiences drawn out from their own personal and professional lives. Self-reflection has been shown to be a powerful tool in learning and continuing medical education conferences (Ratelle et al, 2017a, 2017b). This study echoes some of the results achieved through coaching and its effects on well-being, coping, performance skills, goal-directed self-regulation and work attitudes (Theeboom, Beersma \& van Vianen, 2014). Coaching has been shown to be a powerful tool in educating, training, and helping adult learners practice their andragogy, honoring the transformative learning theory and reflective practice, using experiential learning, while focusing on their values, motivations, and self-efficacy (Stober \& Grant, 2006).

Burnout is an epidemic. The literature talks about solutions by either targeting the antecedent factors or helping individuals deal with it. The literature has looked at several modalities that have worked on an individual level. Of those, we believe that emotional intelligence, self-leadership, and self-care are paramount. Further, given the constraints of time and cost, it becomes almost as important, if not more, to develop delivery methods that will have a practical impact based on the theoretical basis of success. Group coaching is a powerful and transformational approach to help others create behavioral, emotional, and cognitive change. These changes are not only needed, but are necessary to develop the skills needed to combat burnout and thrive in its environment. It is our belief that this workshop and its results shed some light on a successful delivery method, stress the importance of emotional intelligence, self-care, and self-leadership, and perhaps pave the way for future similar interventions. While the workforce is suffering from the dire consequences of burnout, the excuse of cost and time to help support the staff seem to hold less and less merit. The healthcare system is running out of time in supporting its professionals. Hopefully, it is also running out of obstacles.

\section{Funding}

The workshop was funded by Kingwood Medical Center.

\section{Conflicts of Interest}

There were no conflicts of interest.

\section{REFERENCES}

[1] Adams SR, Goler NC, Sanna RS, Boccio M, Bellamy DJ, Brown SD, Neugebauer RS, Ferrara A, Wiley DM, Schmittdiel JA. (2013) Patient satisfaction and perceived success with a telephonic coaching program: the Natural
Experiments for Translation in Diabetes (NEXT-D) Study, Northern California. Preventing Chronic Disease. 10:E179. doi: $10.5888 /$ pcd10.130116.

[2] Ammentorp J, Uhrenfeldt L, Angel F, Ehrensvard M, Carlsen EB, Kofoed PE. (2013) Can life coaching improve health outcomes?-A systematic review of intervention studies. BMC Health Services Research. 13:428. doi: 10.1186/1472-6963-13-428.

[3] Armstrong C., Wolever R.Q., Manning L., Elam R., Moore M., Frates E.P., Duskey H., Anderson C., Curtis R.L., Masemer S., Lawson K. (2013) Group health coaching: strengths, challenges, and next steps. Global Advances in Health and Medicine. 2(3), 95-102.

[4] Anonymous. (2017) "Portrait of a Modern Nurse Survey Finds Half of Nurses Consider Leaving the Profession". https://rnnetwork.com/blog/wp-content/uploads/2017/02/M odern-Physician-Survey-Final.pdf

[5] Bakhamis L, Smith II HL, Coustasse A, Paul III DP. (2017) Burnout Syndrome in Hospital's Nurses: Causes and Consequences. Poster presented at: The Lewis College of Business Research Day; Huntington, WV.

[6] Botha E., Gwin T., Purpora C. (2015) The effectiveness of mindfulness based programs in reducing stress experiences by nurses in adult hospital settings: a systematic review of quantitative evidence protocol. JBI Database System Rev Implement Rep. 13(10), 21-9.

[7] Braun ES, Kinser P, Carrico CK, Dow A. (2019) Being Mindful: A Long-term Investigation of an Interdisciplinary Course in Mindfulness. Global Advances in Health and Medicine. doi: 10.1177/2164956118820064

[8] Codier E, Kooker BM, Shoultz J. (2008) Measuring the emotional intelligence of clinical staff nurses: an approach for improving the clinical care environment. Nursing Administration. 32(1), 8-14.

[9] Dutra HS., Cimiotii JP., Guirardello EB. (2018) Nurse work environment and job-related outcomes in Brazilian hospitals. Applied Nursing Research. (41), 68-72.

[10] El-Aswad N., Ghossoub Z., Nadler R. (2017) Physician Burnout: An Emotionally Malignant Disease. Create Space Publishing. North Charleston, S.C.

[11] Elloy DF, Patil V. (2014) Self-Leadership and Burnout: An Exploratory Study. International Journal of Business and Social Science. 5(9), 7-13.

[12] Gazelle G., Liebschutz J.M., Riess H. (2015) Physician Burnout: Coaching a Way Out. Journal of General Internal Medicine. 30(4), 508-13.

[13] Ghossoub Z., Nadler R., El-Aswad N. (2018) Targeting Physician Burnout Through Emotional Intelligence, Self-Care Techniques, and Leadership Skills Training: A Qualitative Study. Mayo Clinic Proceedings: Innovations, Quality \& Outcome. 2(1), 78-9.http://www.ncbi.nlm.nih.go $\mathrm{v} / \mathrm{pmc} /$ articles/6124346

[14] Gorgens-Ekermans G, Brand T. (2012) Emotional intelligence as a moderator in the stress-burnout relationship: a questionnaire study on nurses. Journal of Clinical Nursing. 21(15-16), 2275-85.

[15] Guo YF, Luo YH, Lam L, Cross W, Plummer V, Zhang J 
(2018) Burnout and its association with resilience in nursing: A cross-sectional study. Journal of Clinical Nursing. 27(1-2); 441-449.

[16] Hardcastle SJ, Hancox J, Hattar A, Maxwell-Smith C, Thøgersen-Ntoumani C, Hagger MS. (2015) Motivating the unmotivated: how can health behavior be changed in those unwilling to change? Frontiers in Psychology. 835,6:1-4.

[17] Hlubocky F.J., Back A.L., Shanafelt T.D. (2016) Addressing burnout in oncology: Why cancer care clinicians are at risk, what individuals can do, and how organizations can respond. American Society of Clinical Oncology. 35, 271-9.

[18] Knowles MS. (2015) The Adult Learner: The definitive classic in adult education and human resource development. $8^{\text {th }}$ edition. Routledge.

[19] Labrague LJ., McEnroe-Petitte DM., Gloe D., Tsaras K., Arteche DL., Maldia F. (2016) Organizational politics, nurses' stress, burnout levels, turnover intention and job satisfaction. International Nursing Review. 64(1), 109-116.

[20] Loschl S, Traut-Mattausch E, Mühlberger MD, Jonas E. (2016) Comparing the Effectiveness of Individual Coaching, Self-Coaching, and Group Training: How Leadership Makes the Difference. Frontiers in Psychology. 629,7: 1-17.

[21] Maslach C. and Zimbardo PG. (2003) Burnout: The Cost of Caring. Malor Books.

[22] Morrison J. (2008) The relationship between emotional intelligence competencies and preferred conflict-handling styles. Journal of Nursing Management. 16(8), 974-83.

[23] Nantsupawat A., Kunaviktikul W., Nantsupawat R., Wichaikhum OA., Thienthong H., Poghosyan L. (2017) Effects of nurse work environment on job dissatisfaction, burnout, intention to leave. International Nursing Review. 64(1), 91-98

[24] Neuner-Jehle S, Schmid M, Gruninger U. (2013) The "Health Coaching" programme: a new patient-centred and visually supported approach for health behavior change in primary care. BMC Family Practice. 14:100. doi: 10.1186/1471-2296-14-100.

[25] Runyan C., Savageau J.A., Potts S., Weinreb L. (2016) Impact of a family medicine resident wellness curriculum: a feasibility study. Medical Education Online. 8(21), 30648. doi: 10.3402/meo.v21.30648.

[26] Ratelle JT, Bonnes SL, Wang AT, Mahapatra S, Schleck CD, Mandrekar JN, Mauck KF, Beckman TJ, Wittich CM. (2017) Associations between teaching effectiveness and participant self-reflection in continuing medical education. Medical Teacher. 39(7), 697-703.

[27] Ratelle JT, Wittich CM, Yu RC, Newman JS, Jenkins SM, Beckman TJ. (2017) Relationships between reflection and behavior change in CME. Journal of Continuing Education in the Health Professions. 37(3), 161-67.

[28] Reith T.P. (2018) Burnout in United States Healthcare Professionals: A Narrative Review. Cureus 10(12): e3681. DOI 10.7759/cureus.3681

[29] Salmoirage-Blothcer E., Fitchett G., Leung K., Volturo G., Boudreaux E., Crawford S., Ockene I., Curtin F. (2016) An exploration of the role of religion/spirituality in the promotion of physicians' wellbeing in Emergency Medicine. Preventive Medicine Reports. 3, 189-95.

[30] Shanafelt T.D., Hasan O., Dyrbye L.N., Sinsky C., Satele D., Sloan J., West CP. (2015) Changes in Burnout and Satisfaction with Work-Life Balance in Physicians and the General US Working Population Between 2011 and 2014. Mayo Clinic Proceedings. 90(12), 1600-13.

[31] Schrijver I., Brady K.J., Trocket M. (2016) An exploration of key issues and potential solutions that impact physician wellbeing and professional fulfillment at an academic canter. Peer Journal. 10;4:e1783. doi: 10.7717/peerj.1783

[32] Schneider S. (2014) Physician coaching to enhance well-being: A qualitative analysis of a pilot intervention. Explore. 10(6), 372-9.

[33] Sczcygiel DD, Mikolajczak M. (2018) Emotional intelligence buffers the effects of negative emotions on job burnout in nursing. Frontiers in Psychology. doi: 10.3389/fpsyg.2018.02649

[34] Stober DR, Grant AM. (2006). Evidence Based Coaching Handbook: Putting Best Practices to Work for Your Clients. $1^{\text {st }}$ edition. Wiley.

[35] Theeboom T, Beersma B, van Vianen AE. (2014) Does coaching work? A meta-analysis on the effects of coaching on an individual level outcomes in an organizational context. The Journal of Positive Psychology. Published online 13 Sept 2013.

[36] Van Wietmarschen H, Tjaden B, van Vliet M, Batties-Fires M, Jong M. (2018). Effects of mindfulness training on perceived stress, self-compassion, and self-reflection of primary care physicians: a mixed-methods study. BJGP Open. 2(4): bjgpopen18X101621. doi: 10.3399/bjgpopen18 $\mathrm{X} 101621$ 